Portland State University

PDXScholar

7-23-2020

\title{
Working From Home: Analyzing the Autonomy of App-Based Adult Content Creators
}

Jenna DePasquale

Portland State University

Follow this and additional works at: https://pdxscholar.library.pdx.edu/open_access_etds

Part of the Sexuality and the Law Commons

Let us know how access to this document benefits you.

\section{Recommended Citation}

DePasquale, Jenna, "Working From Home: Analyzing the Autonomy of App-Based Adult Content Creators" (2020). Dissertations and Theses. Paper 5555.

https://doi.org/10.15760/etd.7429

This Thesis is brought to you for free and open access. It has been accepted for inclusion in Dissertations and Theses by an authorized administrator of PDXScholar. Please contact us if we can make this document more accessible: pdxscholar@pdx.edu. 
Working from Home:

Analyzing the Autonomy of App-Based Adult Content Creators

\author{
by \\ Jenna DePasquale
}

A thesis submitted in partial fulfillment of the requirements for the degree of

\author{
Master of Science \\ in \\ Sociology
}

Thesis Committee:

Aaron Roussell, Chair

Maura Kelly

Tina Burdsall

Portland State University

2020 
Abstract

Accessibility to social media applications ("apps") has paved the way for a new addition under the umbrella of sex work: adult content creation. By selling self-produced photos and videos through mainstream social media apps, creators experience a specific set of conditions unlike the forms of sex work that have proceeded it. Through 13 semistructured interviews, the following question is investigated: What aspects of app-based sex work heighten or threaten workers' senses of autonomy? Autonomy is defined as being able to exert control over one's work and the ability to work without external interruption. It is found that while the demand of being one's own boss can be taxing, working outside of patriarchal organizations allows creators to thrive on their own time and on their own terms. The emotional labor tied to the demand for the experience of a non-commodified sexual relationship is mitigated by creators' ability to set protective barriers. Similarly, sexual harassment from customers can be effectively dealt with through account privacy settings. While adult content creators demonstrate resilience that helps them overcome these barriers, autonomy is significantly impeded upon by the rules and restrictions of apps imposed in the wake of FOSTA-SESTA — a federal legislative package that holds online platforms accountable if human trafficking is found. In the absence of the bureaucratic structures that are present in the formal economy, policing efforts that trickle down from the Federal Government become the organization that enforces gendered inequality and disrupts worker autonomy in informal economic settings. 
Table of Contents

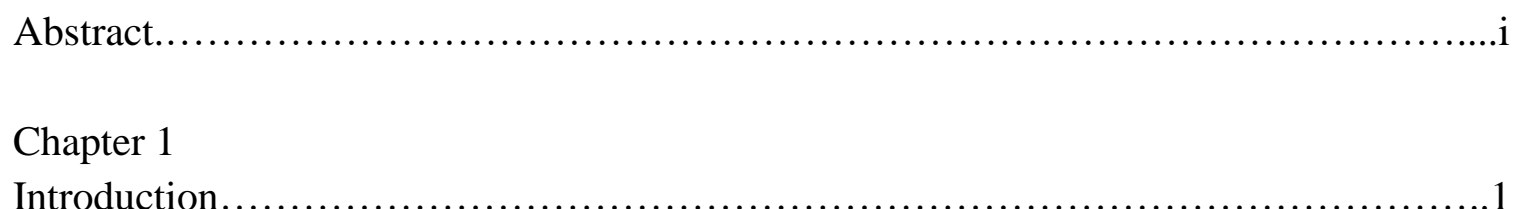

Chapter 2

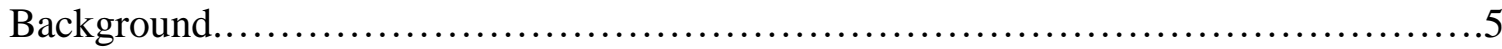

Chapter 3

Literature............................................................... 10

Chapter 4

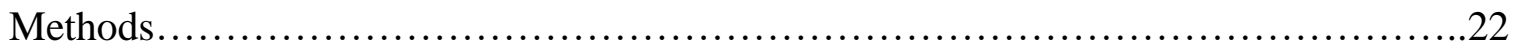

Chapter 5

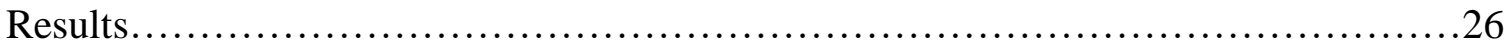

Chapter 6

Conclusion............................................................... 46

References..............................................................51 


\section{Chapter 1}

Introduction

"Girls are profiting off of horny men without leaving their room...if $u$ got anything bad to say about these women clearly you are jealous," tweets one of Twitter's millions of users. Her perspective on the rise of adult content creation - the selling of one's self-produced adult photos and videos on social media apps — is just one of many circulating the internet. Countless perspectives seek to make sense of the monetization of social media presences, particularly as it pertains to sex work, and reasonably so; the story of online sex work, as well as sex work more broadly, is made up of several moving parts that are oriented in theories of gender, work, and policing. Whether sex workers can work consensually without coercion also remains an ongoing debate, which has implications for regulations.

Activist Carol Leigh originated the term "sex work" in the 1970s (Dewey 2012). Sex work, particularly its conception as an umbrella term ranging from full-service prostitution to webcamming, has become common nomenclature across user-generated platforms as adult content creation has become more popular. Adult content creators embrace the label as it serves as a term around which solidarity can be organized. Despite operating under a collective identity, the experiences of female and non-binary app-based adult content creators have largely remained absent among scholarship. The online sphere of sex work has been defined by webcamming, which requires the use of non-mainstream websites and pay-outs to the host. These factors do not apply to adult content creation, which leverages mainstream social media apps. 
Because sex work is often associated with deviance, there is not a robust understanding of the autonomy of sex workers as simply that-workers. Autonomy is herein defined as the ability to exert control over one's work without interruptions from internal or external impediments that affect the ability to thrive in a stable environment. Being able to control factors such as when and how many hours you work are influential in perceived work-life balance, which has implications for workers' health and wellbeing (Guest 2002). Women bear much of this burden, as feminized work is associated with lower levels of authority, and ultimately, autonomy (Jaffee 1989). Contextualizing adult content creation within other technological shifts that challenge or reinforce perceptions of autonomy poses an additional challenge. The umbrella of sex work has historically never provided the kinds of stabilizing worker protections that are being violated by the rise of independent contracting, as is the case on other apps, such as the rideshare service Uber, which conflicts with unionized taxicab drivers. Utilizing an entrepreneurial perspective on social media in order to subsist outside of the formal economy is a way for those who are disenfranchised to earn a comfortable wage; yet, this approach places a barrier to healthcare and social safety nets, and can make one feel as if they are always working (Gença and Öksüzb 2015).

Further complicating understandings of sex work is that it is a feminized laborwork associated with essentialist interpretations of gender - that subsequently demands the mastering of emotion work, unlike other manifestations of the informal economy that focus on the supply and demand of goods and services. Adult content creation specifically exists on hyper-mainstream platforms, which also opens up the possibility for demanding and harassing immediate feedback from which traditional pornographic actors 
have been immune. Yet, accessibility can also be an asset, as more women, gender minorities, and other groups who face discrimination in the formal economy are able to earn incomes on their own terms and challenge historic barriers to their autonomy-an achievement that is denigrated by those who have historically counted on the exploitation of their labor. When it comes to understanding the experiences of adult content creators, the task becomes weighing these conditional pros and cons.

In order to address this gap, the following overarching question is proposed: What aspects of app-based adult content creation heighten or threaten workers' senses of autonomy? This question was investigated through in-depth semi-structured interviews with 13 adult content creators from 2019-2020. It was found that adult content creators do encounter various barriers, such as: managing all aspects of their businesses, providing the experience of a non-commodified relationship, and encountering sexual harassment. However, creators demonstrate resilience in these regards, adapting to these challenges through learned measures. The most significant impediment to autonomy of adult content creators is policing measures stemming from 2018's Stop Enabling Sex Traffickers Act and Allow States and Victims to Fight Online Sex Trafficking Act package (FOSTASESTA). Because online platforms can now be held legally responsible if any human trafficking is found within their boundaries, they are deplatforming creators who post anything pertaining to nudity or sexuality, which directly interferes with creators' abilities to do their jobs and ultimately achieve financial stability. It is found that policing reinforces gender inequalities in the informal economy in the same fashion that bureaucratic structures reinforce gender inequalities in the formal economy, and by the 
same means - undercutting worker autonomy. It will be proposed that the acceptance of all sex work as legitimate work will ensure workers' rights while working to mitigate human trafficking. 
Chapter 2

Background

Social Media

The social media applications Twitter and Instagram are made up of profiles belonging to businesses, public figures, and civilians. These apps can be accessed on desktop or laptop versions but are commonly utilized through smart phones. Apps feature a clean and accessible design. Apps typically notify users when one user interacts with another's content unless this setting is changed. Users share, or "post," videos, photos, links, and written messages, as well as personal information about themselves, which typically occurs in a biography section. Users keep up with what others are posting by "following" them through the click of a button on their profile. Once a user is followed, what they share will show up on the website's homepage, or "timeline," which is cultivated based on an algorithm. An algorithm is used to show the user content they will find most relevant based on the posts with which they engage. Since Twitter and Instagram are free to use, sponsored advertisements are intermittently included among private users' posts in the news feed. The user can click "like" on a post to indicate to the poster that they enjoy or appreciate the content. Posts also have comment sections where users can communicate their feelings about the content being presented. Overall, scrolling through a timeline is similar to reading through a newspaper, except all of the stories are made up of content provided by the friends, family, celebrities, and businesses who the user chooses to follow. Likes and comments add an extra layer of interaction. 
Twitter is specifically composed of "tweets" made by its users, which can include up to 230 characters as well as various photos and videos. Instagram has a greater aesthetic focus; users can edit and post their photos directly through the app, which can be accompanied by captions and hashtags. Hashtags are widely used throughout both Twitter and Instagram. Clicking on a hashtag will take the user to posts from users across the site who have used the same tag. For example, searching \#sexwork on Instagram immediately produces a photo of a woman in a bikini, a feminist zine cover, and a Pikachu meme about sex work clients. For users, hashtags are an important tool for finding more of what they want to see, as well as for attracting new followers to their pages. On both Twitter and Instagram posts can be "liked," commented on, or shared in a variety of ways. There is also an ability to communicate privately user-to-user through direct messages, or "DMs."

The format of Snapchat differs (See Table 1). Snapchat's main innovation was to develop the concept of a "story," or a photo or video that is accessible on followers' homepages for 24 hours before it disappears. Users can also send photos, videos, and written chats privately to one another. In other words, Snapchat effectively eliminates the concept of a personal page; it is not meant to serve as an archive like other social media websites like Facebook and Instagram. This more anonymous and ephemeral element of Snapchat has facilitated its reputation as an app on which sexually explicit communication can occur privately. For example, DMs on Twitter and Facebook cannot be deleted, and their images are pulled by search engines. On Facebook, Twitter, and Instagram, any content, including DMs, can be screenshot without the other person 
knowing, unlike Snapchat. Facebook, Twitter, Instagram, and even YouTube have since incorporated the story concept without eliminating their original concepts. This shift has been linked to Snapchat's declining stock. Nevertheless, Snapchat still survives within the top tier of social media (Nuñez 2020).

Creating content on social media can be a source of pleasure or a means of doing business. Content creation in the broadest sense is the process by which social media users produce the images, videos, and words that they share. However, the term tends to be more specifically associated with those who leverage social media to make money: those who do this are referred to as "content creators." Earning an income on social media commonly comes from brand sponsorships in which creators are paid to promote certain products in their posts. There is also a more do-it-yourself (DIY) approach to monetizing social media. For example, a boutique can operate out of Instagram by posting a picture of a garment and instructing viewers to direct message them about their interest in the product. Logistics can be coordinated through DM, with money changing hands through payment apps like Venmo and CashApp.

Adult content creation largely adopts this DIY approach; a user will post an enticing photo with a caption advertising sexual content and their followers will DM them to complete the purchase. Generally, the creator will request payment before content is sent. On private accounts, coordinating monthly subscriptions is popular. Followers are allowed access to a creator's content for a monthly or one-time fee instead of paying for a la carte content. Subscribers may contact the creator in order to request additional custom content. Like other sex workers, adult content creators experience a 
culture of "regulars," or repeat customers who follow their digital persona. Establishing this trust can add an extra sense of security to transactions. Snapchat customers who screenshot content have their access terminated by the creator. On Instagram and Twitter, creators may watermark their images so that they are traceable back to a specific customer in the event of a content leak. Selling adult content through social media is not illegal, but all users are subject to the terms and conditions of apps.

\section{FOSTA-SESTA}

Sex work has historically been criminalized or highly regulated due to moral and public health concerns. Neoliberal feminism has also produced anti-sex work sentiment that conflates consensual exchanges with human trafficking, as evidenced in the Nordic model, which aims to gradually eradicate the demand for full-service sex work (also known as prostitution) by solely criminalizing those who purchase sexual labor (van der Meulen 2012). The Nordic model is influential in modern approaches to sex work policing, which, at least at the rhetorical level, underscore the importance of ending human trafficking. Human trafficking "involves the use of force, fraud, or coercion to obtain some type of labor or commercial sex act" (U.S. Department of Homeland Security). It is considered to be a form of global modern-day slavery. In response to this issue, The Stop Enabling Sex Traffickers Act and Allow States and Victims to Fight Online Sex Trafficking Act package was signed into law on April 11, 2018. The FOSTASESTA specifically aims to cut down on human trafficking online by amending the Communications Act of 1934 in such a way that "interactive computer services" can be 
subject to state and federal law enforcement (Allow States and Victims to Fight Online Sex Trafficking Act of 2017, Public Law 115-164, Statutes 1253-6).

Opponents of FOSTA-SESTA argue that it leaves companies legally responsible if human trafficking solicitation is found on their websites regardless of their level of awareness. This threat has led some websites to preemptively act. Craigslist, for instance, shut down its "Personals" section in the wake of FOSTA-SESTA and Backpage, an online classified ad service, was shut down entirely (Kennedy 2018). This legislation has also been associated with the increasingly stringent terms and conditions on social media, which has led to the deletion of posts associated with sexuality and the human body (Ettachfini 2018). In one example, the blog hosting website, Tumblr, banned adult content in December of 2018, despite niche, aesthetically pleasing porn being cited as a notable draw to the site (Tiffany 2019). This fear of repression stemming from the conflation of consensual and non-consensual sex work is not new; raids of red-light districts—zones in which sex work services are clustered — can mean roundups and arrests of consensual sex workers (Vitale 2017). When this policing principle is applied within the vast context of the internet, however, it has the potential to affect more individuals than ever before. 


\section{Chapter 3}

\section{Literature}

\section{Entrepreneurship \& General Labor Principles}

Adult content creation can be oriented within the unregulated capitalist principles of the informal economy. Weber (2012) refers to a rational aspiration to work dutifully and industriously as the "spirit of capitalism," which remains at the forefront of principles in the United States. As a result, hyper-productivity is expected of the average American worker as technology has facilitated the speed at which work can be performed, leading to a deficit of leisure time, particularly when compared to European counterparts (Schor 1991). Weber (2012) explains that performing an excess of work in the context of a bureaucratic structure can leave the individual trapped within the "iron cage." Today, bureaucratic structure contributes to the makeup of the formal economy. Rules and hierarchies in established workplaces impede on workers' abilities to control when, where, and how their work is performed. One consequence of these impediments is the inability to achieve work-life balance, which, in modern terms, is particularly obstructed by "factors such as the advances in information technology and information load, the need for speed of response, the importance attached to quality of customer service and its implications for constant availability" (Guest 2002:257).

However, there may be a way out of the iron cage by effectively becoming "the economic agent that was superior to bureaucracy in commanding knowledge, at least regarding their own domain of activity...the capitalist entrepreneur" (Ebner 2005:263.) It is through "entrepreneurial knowledge of private agents" that allows for "potential 
immunity from the ubiquitous drive for bureaucratic rule" (p. 263). This principle entails exerting autonomy by working for oneself without having to adhere to established protocol and administrative hierarchies. While creators are still selling their labor and do not function as capitalists, running a business primarily through social media is an accessible way to act as an entrepreneurial agent, particularly as startup costs remain exceptionally low (Genç and Öksüzb 2015). In addition to requiring a low financial investment, social media helps workers tap into larger creative streams. In terms of satisfaction, being able to utilize one's creativity at work is associated with a more positive affect overall, prolonging workers' ingenuity and longevity (Andersson and Harnois 2020; Tavares 2016).

Adult content creators largely work outside the context of formal economic structures, particularly as compared to other forms of legal sex work. While most legal sex workers area able to practice control over their work through benefits like flexible schedules, adult content creators are unique in that they are not bound to independent contractor agreements, such as dancers or webcam models, who owe a portion of their earnings to their platform hosts. Still, adult content creation is not immune to other effects of political economy that may serve as external impediments to autonomy. Key institutions of industrial relations include the state, the management, and the worker (Edwards 2003). The role of the state in sex work more broadly has been of surveillance, perhaps due to the absence of bureaucratic rule that enforces the domination of labor (van der Muelen 2012). In the same fashion that dancers have their physical expression limited by state and municipal laws, online sex workers have their expression limited by the 
trickle-down effect of FOSTA-SESTA on social media, which disrupts their flow of work (Ettachfini 2018). Thus, the state's role in labor has a pertinent effect on the reinforcement of economic inequalities by obstructing worker autonomy. In the formal economy, Acker (2006) refers to reinforcers of gender stratification as "inequality regimes," which are formally defined as "the interlocked practices and processes that result in continuing inequalities in all work organizations" (p. 441).

Those who work in the informal economies tend to have few opportunities to work autonomously in the formal economy, as they are "marginalized by ethnicity and race, immigrant status, or geographic isolation," as well as gender, and "who have no economic alternative" (Miller 1987:30). The entrepreneurial elements of adult content creation — building one's own brand to attract a growing customer base — can be interpreted as a way that female-identified individuals tap into financial autonomy in the absence of a hospitable formal economy. One impediment to women's success in the workplace is inflexible scheduling. According to Acker (2006), being able to control when one works is written into the design of many jobs. In her words, work is "organized on the image of a white man who is totally dedicated to the work and who has no responsibilities for children or family demands other than earning a living," and is supported by compliant lower-level employees, who are generally women (especially women of color) (p. 448). Unequal treatment does not go without notice, especially by those who are the most vulnerable in the labor market. Women with lower levels of education, who are among the most vulnerable in the labor market, experience a decline in health and workplace satisfaction when they encounter internal impediments to 
autonomy such as being discriminated against or harassed because of their gender (Andersson and Harnois 2020). Still, women at all levels experience barriers; while some have access to full-time upper-level positions within the formal economy, they are still subject to sexual harassment and gendered earning gaps (McLaughlin 2012; US Department of Labor). These barriers reflect a lack of autonomy as it pertains to working conditions and financial outcomes.

While the informal economy may serve as an alternative to regimes of inequality, it comes with limitations. For example, working outside of the formal economy has been associated with a lack of benefits that would otherwise stabilize income, ultimately, "keep[ing] women indoors without any social security rights" (Gença and Öksüzb 2015:295). In a study of webcam models, van Doorn and Velthius (2017) find that the entrepreneurial language of the "hustle," as it is described through vernacular of the informal and underground economies, perpetuates meritocratic ideology while failing to account for limitations such as the oversaturation of workers and embedded racial inequalities (Jones 2015). Bernstein (2007) also describes those who have reaped the benefits of technological shifts in sex work as "relatively privileged" people who "have entered into commercial sexual encounters in response to new subjective and social meanings that append to market-mediated sex," or, simply, the lessening of stigma (p. 37). More broadly, anarchist feminists also argue that reproducing capitalist principles through entrepreneurship is antithetical to women's liberation, as private property perpetuates inequality and dependence (Ferguson et al 2019).

\section{Feminized Labor}


Sex work is a form of feminized labor because it has historically been disproportionately performed by women, as well sexual minorities who are also subject to inequality based on heteronormative patriarchal structures. Sexual harassment and gendered microaggressions women may encounter in these institutions further alienates women from the image of the ideal bureaucratic worker. Feminized labor also pertains to how women are assigned to the most stringently bureaucratic institutions in the formal economy, such as education, the government, and corporate entities. Guy and Newman (2004) point to how the gendered division of labor accounts for the pay gap because the performance of emotional labor — the hallmark of many traditionally female roles - is devalued. Feminized labor thus makes up one half of an essentialist whole: Women have a universal capacity to perform emotional labor, and men have a universal capacity to perform physical labor. In addition to emotional elements of formal feminized labor, there are practical constraints, such as "poor working conditions, low pay, narrow job content, little opportunity for autonomy, few promotions prospects, stereotyped gender attributes that serve to perpetuate their segregated nature," and other barriers to autonomy (Truss 1993:562). Secretaries, for example, are in a ghettoized labor pool in which promotion is unlikely and work stressors are associated with declining mental health, and paralegals must play an active role in reaffirming the predominantly male lawyers they serve (Pierce 1999; Truss 1993). Jaffee (1989) underscores the devaluation of feminized labor by noting how "women are segregated into occupations that minimize the likelihood of exercising autonomy and supervisory authority," and are unlikely to hold decision-making authority even in traditionally female sectors (p. 387). 
The conceptualization of sex work as feminized labor developed as feminist movements expanded throughout the 20th century. Dewey (2012) notes that "feminized labor is often highly regulated despite the relative lack of benefits and income it provides to its workers, and this regulation increases exponentially with the degree of stigma attached to particular forms of feminized work" (p. 117). For instance, exotic dance is subject to laws that are enforced through covert and overt police operations that are not intended to ensure fair labor practices, but instead reinforce that the majority of dancers remain independent contractors with few worker rights (Price-Glynn 2012). Essentially working for oneself and merely renting time on stage also "enable[s] women to retain partial control over their pay" unlike other workers in the club-bartenders, bouncers, deejays—who are at least, in part, wage laborers (Price-Glynn 2012:146). Price-Glynn (2012) goes on to note that this structure can pit dancers against one other, and this hustle can become more intense when the market becomes increasingly saturated, as has been the case in webcamming (van Doorn and Velthius 2017). Maher et al. (2012), however, find that indoor full-service work is a way of earning a livable income on flexible hours, which they link to "flexibility compared to broader gendered employment conditions" and a lack of "comparable employment" (p. 654).

Emotional labor is an influential factor in sex workers' sense of autonomy by inserting an additional layer of labor that must be performed in addition to providing a sexual service. While the degree may vary based on specific profession, sex workers are to provide a sense of authentic intimacy known as the "girlfriend experience" through deep acting, which involves aligning verbal and nonverbal language with the emotions 
the worker is expected to feel. This expectation is especially salient for sex workers like escorts, who offer company instead of or in addition to sexual acts (Carbonero and Garrido 2017). Elements of both surface and deep acting can be found when delivering the physical service or performance itself. Frith (2014) notes that the authenticity of female pleasure is tied to heteronormative rules. Commercial sex workers like mainstream pornographic actors as well as women in noncommodified relationships may engage in surface acting to order to "disguise what they really feel (by suppressing disgust or boredom or by feigning desire and climax) in order to protect men from feeling sexually inadequate or conversely to induce pleasure" (p. 393). Traditional pornographic actors and other commodified workers engage in deep acting by attempting to derive genuine pleasure as a barrier for repulsion or disinterest. Overall, Frith (2014) maintains cultural anxieties surrounding female orgasms need to be studied more extensively in order to understand the full extent of the gendered power dynamics in which they are entrenched. In a study of webcam models, on the other hand, Jones (2016) asserts that there is potential for the worker to experience "sexual and affectual pleasures" because the "computer-mediated sexual exchange acts as a psychological barrier, and that the computer in turn becomes the primary tool that performers use for emotional management" (p. 227). While some sex workers may find emotional labor taxing and time-consuming, others may find that these performances make their working conditions more uniquely their own, particularly when taking advantage of the distance that a digital platform may provide.

Harassment \& Inequalities 
Workers lose control over their working conditions when they encounter hostile environments, as fear and degradation affect the ability to be present both physically and mentally. Non-commodified sexual relationships that are mediated through the internet, especially popular apps, are not necessarily positive experiences. Sexting culture, or the non-commodified exchange of adult content, is linked to sexual coercion and harassment (Stanley 2018). Indirect cyber abuse, which humiliates the victim through public posts, is more common among familiar victim-abuser relationships, while direct cyber abuse, which is sent directly to the victim, is more common among strangers (Vakhitova et al 2018). When applying this finding to commodified relationships, sex workers are subject to abuse whether they deploy the experience of a non-commodified girlfriend or if they try to maintain a sense of distance. The dating app Tinder, which is intended to provide its users with a non-commodified experience, has also been shown to maintain racist sexual scripts that leave people of color more vulnerable to discriminatory practices and racist language, perhaps under the guise of alleged sexual preferences (Christensen 2018). In other words, the internet can be a hostile place, particularly for those whose identities are also met with hostility in other arenas of society, which negatively impacts their visibility.

Jones (2015) shares similar findings in terms of commodified relationships, citing how "racialized stereotypes affect ideas about bodily aesthetics; for example, "clients might consume escort services based on stereotypes, such as black men having larger penises, or different racial groups having different amounts of body hair” (p. 791). These projected racial stereotypes become barriers to sex workers as they lose control over 
which corners of the industry in which they can work, as well as how their image that they invest time in cultivating is perceived. In traditional pornography and webcamming alike, agents and/or models check off certain boxes that describe the performer's race and body type, which places women of color in separate categories. Price-Glynn (2012) notes a similarly segregated experience in the strip club. While tapping into fetishized images may seemingly increase earning potential for workers of color, stereotypes reinforce racial inequalities that thwart their entry into mainstream work. Thus, Jones (2015) goes on to assert that "the racial disparity in wages found across labor markets" can also be found in sex work. On one webcam site, a significant relationship was found between whiteness and high cam scores, which measure earnings (Jones 2015:789).

More broadly, the client discretion that webcam models and internet-based fullservice sex workers enjoy can be undermined by instances of harassment, which have become more egregious through technological advances (Sanders et al. 2016). While the solution to cyberbullying can be as simple as terminating a Snapchat subscription or blocking the associated username, trolls — internet users with the goal of making inflammatory comments—-sometimes make fake accounts to taunt their victims. Still, some evidence suggests that there is room on the internet to challenge stigmatizing narratives that hamper the empowerment of sex workers. Handyside and Ringrose (2017) highlight the gendered language that guides the exchange of sexual content on Snapchat in non-commodified heterosexual relationships; subsequently, sexual scrutiny is more often pinned on the female participant by other app users. But, by using humor, women are "able to take back some agency over the harsh sexual judgements they had been 
subject to," by poking fun at the "simplistic sexualized readings boys had applied to their selfies" (p. 354). Handyside and Ringrose (2017) also find that Snaps serve as a form of "relationship currency," suggesting that some adult content creators may be hijacking control over their own sexualization in exchange for more literal currency. More privileged sex workers are also able to voice their experiences and surrounding attitudes through blogging, which has the potential to change attitudes towards the commodification of sexuality, and ultimately, restore their sense of humanity (Bernstein 2007). It is unclear if this narrative shift may also come to enhance the autonomy of less privileged sex workers, or if it will only offer a one-dimensional advantage.

\section{Policy \& Policing}

While the umbrella of sex work runs the gamut in terms of legal status and how it is policed, one consistency is that public policy affects how sex workers do their jobs. In the United States, full-service prostitution remains illegal with the exception of eight counties in Nevada, which require specific licensing for brothels to lawfully operate. Full-service work persists nevertheless in known prostitution zones often called red-light districts, which are subject to mass detainments and subsequent arrests (Vitale 2017). As discussed, stripping in major U.S. cities, while legal, is subject to local laws that may dictate everything from the permitted level of nudity to club zoning (Cook 2005; Parthasarathy 2019). Dancers' statuses as independently contracted workers who are subject to police surveillance and few employment rights make it difficult to orient the craft within either the informal or formal economies. Similar to webcamming, adult content creation is not illegal, but it is subject to the terms and conditions of apps, which 
dictate what kind of content is and is not allowed to be shared on the platform. However, these rules guide the vast array of content on platforms like Instagram and Twitter and not just the more niche communities found on camming websites.

While sex work has historically been policed due to concerns regarding morality and public health, a recent wave of neo-liberal feminism has deemed all forms of sex work, especially full-service, inherently exploitative, thus calling for its eradication (van der Muelen 2012; Women's Coalition for the Abolition of Prostitution). The key way through which they plan to implement eradication is through the adoption of the Nordic Model, which criminalizes only the purchasing of sexual services with the goal of "preventing prostitutes from earning" and "pressuring them into abandoning the trade [and] discourag[ing] trafficking in women" (Danna 2012:80). Linking full-service work as a whole to human trafficking leaves little room for a model in which prostitution can be carried out legally through the consent of its workers. FOSTA-SESTA does not solely seek to prosecute those purchasing sexual labor. Its goal of cracking down on human trafficking online targets clients, but also the online mediums that host advertisements offering sexual services. Still, the legal package's lack of consideration for sex workers who are not being trafficked retains the abolitionist nature of the Nordic Model. Impeding on all sex workers' spaces not only perpetuates the idea that all sex work is coercive, but it also limits opportunities to earn money outside of the patriarchal formal economy.

In sum, several questions emerge from current literature. A question arises when it comes to the entrepreneurial qualities of adult content creation: is it a way to opt out of patriarchal structures for those who have the option, or, a space for those who are 
disenfranchised from the aboveground economy entirely, but at what cost? Sex work also has advantages and disadvantages over some kinds of feminized labor, yet it is unclear where adult content creation falls on this spectrum. It is also ambiguous whether internet accessibility's facilitation of harassment and discrimination is counterbalanced by the adult content creator's ability to assert their own identity and perspective, ultimately leading to financial success. Finally is the question of how the expansion of policing into the online sphere of sex work has affected adult content creators.

These questions are bound together by the theme of autonomy as it has been previously defined, and how it may or not be able to be utilized in the process of adult content creation. Whether or not sex work is empowering is a long-contested topic, but this research aims not to firmly confirm or deny empowerment, but rather, understand how power is practiced and revoked. By contrasting adult content creation with other kinds of sex work, this research challenges the notion that sex workers are a group with a singular exploitative experience. Such an analysis will provide insights into how the informal economy may challenge or reinforce the inequality regimes found in other kinds of feminized labor across various economic levels. 
Chapter 4

Methods

This project utilized 13 in-depth qualitative interviews in order to address the following overarching research question: What aspects of app-based sex work heighten or threaten workers' senses of autonomy? Participants had to be female-identified or nonbinary individuals over the age of 18 who sell their self-produced adult content through social media apps. Cis men were not included at this stage in order to account for certain gender privileges that may skew perceptions of autonomy. The sample was restricted to the United States to account for the federal jurisdiction of FOSTA-SESTA. Participants were drawn from Louisiana, Tennessee, Pennsylvania, Illinois, and Oregon. All adult content creation is legal in all 50 U.S. states. While internet access has flattened some regional boundaries, location was considered when making comparisons to other kinds of sex work (e.g., Stripping is subject to local laws that vary). Recruitment yielded a convenience sample through purposive snowball methodology. I first tapped into an exclusive network of adult entertainers based in New Orleans, Louisiana to which I gained access through the assistance of an insider friend. In order to reach individuals, flyers were also disseminated across social media, often with the help of previous respondents in their respective online networks. These methods produced 13 interviews with participants ranging from ages 22-39. Eleven participants were white with one identifying ethnically as Romani, and two participants identified as mixed race. Twelve participants identified as female and one, non-binary. 
Each semi-structured interview took roughly 40-90 minutes of each participant's time. The general interview frame addressed a wide range of topics in order to target as many facets of app-based sex work as possible. Some of these topics included how they engage with social media (e.g., What branding techniques do you use?), what goes into a performance (e.g., How do you prepare for work?), the relationship with their buyers (e.g., How do you engage with your customers?), and run-ins with harassers and social media terms and conditions (e.g., Has your account ever been deleted or banned?). Follow-up probes were implemented where appropriate.

Each interview was conducted through July 2019-March 2020 via phone, with the exception of one in-person meeting at the participant's request. Calls were either conducted from my office or my apartment and participants spoke from the privacy of their homes or vehicles. Interviews were audiotaped through the app Call Recording Now and were protected by my phone's passcode. The transcriptions are held in files encrypted through VeraCrypt and Microsoft Word. All material was saved in accounts to which only I have access. All legal names were removed and replaced with pseudonyms with the exception of informed consent forms and one document that housed all contact information. It was my goal to create an approachable environment in order to be a medium for the voices of app-based sex workers. Because my demographics largely match those of the participants, I remained hopeful that I could be a source in which they could confide. However, being white and cis may have discouraged the attraction of a more diverse sample. 
The analysis process involved three rounds of coding for related themes. Because the research questions analyze both threats to and bolsters of autonomy, codes often read dichotomously. For example, "burnout" and "resilience" were two subsidiary codes of "emotional labor." "Harassment" was also further divided by "cyberbullying" and "social media jail" in order to account for various sources of tension to which creators could be exposed. This coding method was able to highlight how harassment from app administrators leads to more long-term detrimental effects on careers.

All but one participant engaged in other forms of sex work, and all participants engaged in other forms of work more broadly. While exotic dancing was the most common form of sex work being performed besides adult content creation, there were also full-service workers, webcammers, and niche fetish workers. Other jobs mainly consisted of service and sales duties as well as entry and mid-level office work. Some were pursuing school currently or in the near future. Experience in non-adult modeling and dancing was also frequently referenced. This artistic interest also manifested in ventures such as photography, fashion design, painting, alternative culture, and general aesthetic appreciation. Participants were financially independent, with two citing that they had family to whom they could turn in case of an emergency. Committed relationships in the form of marriages or cohabitation were common. One participant had a child and many participants held close relationships with their pets. While specific income levels were not discussed, there was a general sense that "getting by" was possible in their current situations. 
While some engaged in sex work activism, others stated that they did not engage as much as they would like. Adult content creators who use their platform to discuss sex worker issues were likely attracted to the study, but they were not purposefully sought out. Activists represent a more privileged kind of sex worker as they have the ability to speak for a highly stigmatized group. The most fervent activists in the sample acknowledged that they were enjoying these privileges, which they largely attributed to being white. Homogeneity within the sample will be discussed when addressing the limitations of the study. 


\section{Chapter 5}

Results

\section{The Hustle}

Themes of entrepreneurship emerged in how participants pieced together different income streams - sex work-related or otherwise - in order to achieve financial security. Adult content creation essentially filled in gaps in autonomy in other jobs. Either due to crackdowns in other kinds of sex work or jobs in the formal economy failing to make ends meet, online sex work was recognized by participants as a new chance to expand their incomes. Subsequently, participants developed their own hustle, which is made up of a web of gigs and cross-marketing techniques. Adult content creation is an ideal supplement to other work or personal responsibilities due to its flexibility. The hustle mentality can be overwhelming in the informal economy, as it comes with unpaid labor and tax disadvantages, which are associated with lower levels of autonomy. This pressure is more intense for participants who treat adult content creation more like a full-time job or a traditional pornographic business. However, creators are highly adaptable, discovering loopholes throughout the learning process that helped them most effectively leverage their time and money.

Participants can pinpoint the instant when they learned about the principle of adult content creation. While driving one day, Nikki, 27, heard a National Public Radio broadcast about how traditional pornographic actors were shifting to the format of adult content creation, as creating custom content has proved lucrative in spite of the abundance of porn found online. "I know that there's free porn all over the internet but it 
lacks that personal connection, and I found that that's what a lot of guys in particular are looking for...it's that little personal attachment that's coming from that intimacy you don't get from a free porn site," elaborates Shauna, a 35-year-old woman who also works a project manager. Recognizing this demand, participants entered the budding world of content creation. More specifically, their motivations involved supplementing other forms of income. While Shauna expresses that she has no shortage of clients at her "vanilla job" (a term used to describe jobs outside of adult entertainment), content creation allows her to save money for certain events, such as preparing to move homes. For others, adult content creation has been a key supplement when it comes to leveraging their time, particularly when autonomy in other forms of sex work is impeded on, suggesting the devaluation of adult entertainment spearheaded by policing. Veronica, a 39-year-old dancer and freelance writer, sends her regular customers at the club to her monetized app-based persona so that she is not communicating with them for free via text message. Mandy, a 27-year-old psychic from New Orleans, expresses how since Bourbon Street clubs were raided in January of 2018, there has been a "steady decline in business." As a result, she says that adult content creation serves as a necessary cushion, stating 'I'm honestly just trying to be a jack of all trades because I mainly kind of have to be now."

While some participants connected the need for income supplementation to sex work-related crackdowns, others connected it to additional macro-level forces. Aaliyah, a 24-year-old woman who takes an active role in sex worker advocacy, says the following: 
[Adult content creation is] similar to camming, but there's really not a lot of money in camming... because everyone is a cam girl, which is fine. Prior to the French Revolution, one in five women was a sex worker, so I think it's just a reflection of the state of the economy. More people are turning to work like that and there's not much you can do about it.

Aaliyah connects the oversaturation of webcam models to a lack of more lucrative jobs for women and the devaluation of feminized labor. Consequently, individuals are exploring adult content creation while it still provides a chance for prosperity. She also goes on to describe how adult content creation offers flexibility that most jobs in, say, low-wage service and administrative roles do not. Because of her chronic pain syndrome and digestive disease, she is disempowered by set schedules with no breaks. "It's something where if I need to go to the bathroom and I'm going to be in there for an hour, nobody's going to be knocking on the door accusing me of being on my phone the whole time," she says. Skyler, a 22-year-old non-binary student, echoes this sentiment in other kinds of sex work, describing how mandated 14-hour shifts at the strip club were unrealistic due to their chronic pain. Having the power to create small bouts of content from home has been gentler on their body in addition to being complementary to their school schedule. Lilah, a 24-year-old mother and webcam model, has found that online sex work has allowed her to make money efficiently while her son is at daycare, as opposed to dancing, which also conflicted with her painful neurological condition. Veronica exemplifies why adult content creation can be one of the most efficient ways to earn money:

I'll start talking to someone and they'll be like 'oh, what are you doing?' and I'll be like 'oh, just taking a bath,' and then I'll just send them pics of me in the bath and by the time I've gotten my coffee, I've already made 
\$50. It's amazing to feel like whenever you want money you can dip into this stream that's always flowing.

By being able to monetize everyday activities without having to leave her home or spend time on a webcam stream, Veronica is practicing her autonomy by maximizing her time on her own accord, oscillating between content creation and freelance writing throughout her workday.

The hustle, however, does not necessarily come without stress, echoing the demand for constant availability and consistent flows of information described by Guest (2002). Emma, a 30-year-old member of her local queer porn scene, describes what she refers to as "porn mind." Porn mind is essentially a form of guilt that arises when she is not leveraging every chance she gets for a sexy photoshoot. Veronica describes a similar form of guilt when she chooses to enjoy a day at the pool without feeling compelled to take photos of herself in her bikini. As Emma goes on to describe:

It's really hard when you have 'porn mind' where you're like 'oh, I'm going to go for a hike, maybe I can shoot a scene there.' It's just so hard to disengage because it's like you're always thinking about things that you could do to keep a following or keep people interested and I think that's maybe just different from being an independent contractor who's hired to do scenes all the time because then you don't have to do all of that brainpower.

More freedom can come with more unpaid labor, a paradox unique to entrepreneurial employment; while a traditional pornographic actor performs, an adult content creator also fills the role of the videographer, director, and editor while only being compensated as the performer. In order to regain autonomy by mitigating some of this stress and bolstering the quality of their content, Emma, as well as Riley, a 36-year-old dancer at a longstanding club, will collaborate with other creators and videographers. However, she 
notes that it can be hard to find reliable people who will not waste her time, and ultimately, her money. Emma explains that producing the most lucrative content causes her to feel as though she is always working. While she is able to manage her 40-hour-aweek adult content creation business during downtime at her vanilla job, becoming her own boss has come with a learning curve in terms of work-life balance. Having to engage in unpaid labor with the hopes of striking a windfall is a problem for all kinds of sex workers, who are not paid hourly wages. For example, Skyler, who began their journey into sex work with full-service, describes how the process of pre-screening clients can prove to be a bust if they are not serious customers (or, potentially dangerous). Mandy also describes how "[sex work] is only draining if you're not making money." As a result, she likes to film videos dancing on the pole at her club to upload online when there are not any in-person customers to entertain.

While filing taxes provides access to social safety nets in some scenarios, there are tax disadvantages that impede on the autonomy of self-employed workers. Adult content creators are ineligible for the tax breaks that corporate businesses in the formal economy enjoy. They are also responsible for both employee and employer portions of taxes. Contrary to public perception, online sex workers pay taxes (and a lot of them). Because adult content creation leaves a digital paper trail, it is considered unwise not to file, particularly for the most lucrative creators. Lilah describes how webcam models have similar experiences, as most sites issue tax forms or earning statements. One of her webcamming friends enlisted the help of a tax attorney, who effectively took her money and ran. As a result, she still owes tens of thousands of dollars to the IRS. However, 
Lilah, among others, has found that also working a job that issues a W2 helps balance out what taxes are owed and what is returned. Additionally, learning how to piece together income streams in the most strategic fashion (e.g., Mandy filming her pole dancing), helps mitigate the amount of unpaid labor being performed.

While the hustle both bolsters and impedes upon autonomy, adult content creators learn how to cater their work to their lifestyles in a way that maximizes their income. Classifying sex work as "real work" that is of equal worth to bureaucratically structured jobs in the formal economy would keep adult content creators from facing factors such as policing-related insecurity and an undue tax burden. Ensuring that the income stream of online sex work is not impeded upon by these factors would keep already vulnerable populations - women and/or sexual minorities - from enduring additional disadvantages in the workplace. Aaliyah addresses anarchist feminist concerns, stating, "Even though I came from poverty I wouldn't say I was coerced into [sex work], but I think capitalism is inherently coercive." While it is perhaps impossible to achieve complete liberation in any sector of the economy, Aaliyah sees online sex work as exploitative insofar as all paid labor is exploitative.

\section{The Girlfriend Experience}

The emotion work performed in adult content creation is largely defined by the girlfriend experience, or how content and communication provide the sense of a noncommodified relationship. Because adult content creation largely leverages mainstream apps, selling an authentic girl-next-door type of image is considered more desirable, as opposed to other kinds of sex work that capitalize on a hegemonic feminine ideal. The 
ability to sell one's organic likeness expedites the process of creating content. However, it does not come without challenges to autonomy - mainly, walking the tightrope of being like someone's girlfriend without having to perform excessive unpaid labor. Nevertheless, participants have learned how to exert control be setting boundaries, even when creating custom content, in such a way that maximizes their bottom-line while being able to maintain a sense of distance from working relationships. Engaging with hobbies, non-commodified relationships, and charity work serve as relaxation rituals that help manage their well-being in their off time. Other participants enjoy the connections they make at work; therefore, they do not mind investing additional time by serving as an emotional support system to their customers, as it leads to fulfillment in their jobs. Enjoying this process serves as an incentive to produce more content, and ultimately, adds longevity to their business.

Participants invest in a sense of performative intimacy in which they engage in girlfriend-like correspondence and imagery. Adult content creators must negotiate performative intimacy carefully because, as Veronica notes, "their holy grail is always 'oh, let me get you off this app."' Shauna finds herself increasingly straddled between what is "real" and what is effectively just a business for her. She feels safer working through a word-of-mouth system with customers being referred by friends and acquaintances. However, this comes with the price of having to utilize her personal social media in lieu of separate sex work accounts:

I think one of the boundaries that's pushed [is that] I don't have any separate accounts, like I use my regular Facebook and my Instagram. I think that makes it a lot harder for men to understand that it is still kind of just a job for me. I don't want to meet them in real life. I don't want to be their 
girlfriends and I think that's a lot harder when you're creating, and maybe that's because I make girlfriend experience-like content. It definitely makes a big difference in trying to keep those boundaries respected.

After growing tired of leveraging her Snapchat for adult content creation, Veronica decided to try out a new app called Phrendly. Phrendly, along with pay-forcontent sites like OnlyFans, is an example of how technology is catching up with the demand for adult content creation in such a way that hyper-mainstream apps do not need to be utilized. Veronica enjoys Phrendly because it has built-in protections for creatorstransactions go securely through the app, and it has strict instructions to only interact with users within the online sphere (the app's tagline is "Real relationships, Only Online"). However, Phrendly, which monetizes conversations between the creator and the consumer, is distinct in that it is "very much cloaked in traditional dating vernacular," as Veronica describes. The structure of Phrendly helps Veronica make better use of her time in that she is paid a fraction of a dollar for every message she sends-interactions that she must typically do in the strip club for free. However, the app's imagery also adds ambiguity to its transactional nature that has the potential to encroach on protective boundaries:

It's usually male users, but they have the option to send you gifts [in the form of illustrations], but it's really just money in certain increments. You might be like 'send me chocolates' but that's really $\$ 25$. And it's like oh okay, he gave me $\$ 25$, so here's a picture of my butt or something like that.

Another method through which adult content creators provide the girlfriend experience is by acting as "the girl next door." Diverging from traditional pornographic actors who tend to sport hyperfeminine, hypersexualized images, adult content creators' brands often mean not having a brand at all. Accordingly, the getting ready process for adult content 
creation involves tweaking lighting as opposed to fixing hair and applying false eyelashes, as is the case for preparing for a shift at a strip club where autonomy over a dancer's appearance is monitored by club management. While some maintain a sense of distance by utilizing separate sex work accounts and pseudonyms, the semblance of engaging with a "real" person's content and not a distant pornographic actor must still be provided. As Belle, 28, a Memphis-based creator with full-service experience elaborates, "a lot of middle-aged men kind of look for that because they think they're trying to relive their high school/college days." The seeming contradiction of selling an escapist experience while also selling one's own personality can be exciting in that it allows for the use of humor and creativity, which ultimately bolsters the autonomy of a creator's presentation. Olivia, a 27-year-old dancer, for example, developed her fondness for sloths into a mascot, photoshopping one of the subdued mammals into her photos and using their likeness to advertise her dancing schedule. This wholesome, relatable identity has been so successful that one of her followers is now paying for her to get a sloth tattoo. In other instances, acting as the girl next door is more mundane. When describing what she posts on Instagram, Shauna states the following:

I'll do some cute little gym pictures and stuff like that, which actually draws me in an okay crowd of guys who are interested in purchasing content. I think they like the allure that it's not a sex worker, it's a normal girl who's breaking the rules a little bit.

While walking the tightrope between being a sex worker and a "real" app user can be awkward, respondents demonstrate a kind of resilience that protects their time and effort. All participants offer custom content services in order to satisfy the requests of their consumers, which requires the ability to transform ideas into a dynamic photo or 
video. Requests pertain to what clothing is worn, what props are used, and what part of the body is accentuated. All participants report feeling as though they are able to assert their boundaries when a request becomes more uncomfortable or demanding than it is worth. Lilah describes how taking control over custom content makes it "a lot less tedious":

So, a lot of girls are moving away from custom content and they're doing custom ideas. So instead of being like 'I really want you doing this, this, and this at 34 seconds--because men will send you a screenplay of what they want you doing every 10 seconds--you do custom ideas, which is where they'll be like 'I want you in a cat girl outfit, I want it to be 10 minutes, and I want it in this position.' Then you can make it how you want it without it being a literal porn screenplay. Because men think we're bending to every whim and I've found custom ideas to be a little easier, so a lot of women are moving towards that.

Being able to cater to the market of custom content while still ultimately holding the reins is a way for adult content creators to express their autonomy, as they have the final say on what is being created. When it comes to customer interaction more broadly, Lilah describes how a certain customer with whom she was engaging was ultimately becoming too needy, requesting that she entertain phone calls in which he declared love for her. While she acknowledges cutting him off was seemingly risky, the money she was making from him was being spread thin across her work hours due to his excessive need for attention. She has learned to prevent similar scenarios by informing her customer base that she has a set work schedule, ensuring work-life balance and mitigating unpaid labor. Other participants also developed a work window, such as Veronica, who multitasks from 9:00 a.m. to 6:00 p.m. Adult content creators also prevent burning themselves out, which has consequences for the longevity of their businesses, by engaging in various relaxation 
rituals, such as reading books, listening to podcasts, spending time with pets and significant others, exercising, crafting, smoking cannabis, and resting their bodies. Belle, in addition to attending a sex work-positive therapist, has also started embracing Quakerism. She explains that her local chapter was "collecting teddy bears for the child advocacy center, which is basically where kids go when they're victims of sexual or domestic abuse, so I took a sack full of new teddy bears and attended my first Quaker friendship service." Other participants find support in sex worker-friendly spaces. Allowing for meaningful time off ultimately fosters greater productivity during their "on" time, as their energy is recharged.

It should also be noted that a couple of participants find the human element of their work as a source of passion that also facilitates their willingness to work. Twentyfour-year-old model Angel finds that the emotional labor she employs to be fruitful in terms of performing self-actualizing work. "I really like it as long as the client and I get along and there is mutual respect," she explains. "I actually really have had positive experiences where I feel like I've helped clients grow by not only pulling them out of their comfort zone but offering them guidance and support." When she feels comfortable enough to transcend performative intimacy in order to build genuine human interactions, she discovers a kind of fulfillment that can be otherwise tedious to achieve in serviceoriented labor. Mandy echoes this sentiment when it comes to content creation, as well as sex work more broadly, stating, "I love what I do and I like making people happy...I mean, you don't owe them anything that you can't readily give away, so you have to be able to realize what your gifts and talents are and be ready to share them with the world." 
In other words, sharing her people skills entices her to work, but can also be retracted if a customer's demands exceed what she wishes to give.

Adult content creation fits into the category of feminized labor because maintaining a sense of authentic intimacy, as well as catering to the needs of men, is at the forefront of the demand for content. However, it differs from other forms of sex work in that selling relatability, or the authentic image of an app user, is valued over the elaborate fantasy of an adult entertainer. Selling the image of the girl-next-door without overextending their emotional labor — and ultimately, their time — is a balance that creators ultimately learn how to strike in order to preserve their autonomy. Being their own boss is a major factor in creators' abilities to assert their boundaries by moderating requests and setting work hours, which represents a level of power that is largely absent from feminized labor in the formal economy. The enjoyment that some participants get out of the human element of work prevents feelings of alienation that would otherwise discourage them from selling content. In sum, while adult content creation demands emotion work, its context in the informal economy makes it moldable to creators' personal boundaries and profit motives.

\section{Cultivating Their Experience}

Harassment and inequalities hold the potential to run rampant on user-generated platforms, and ultimately, adult content creators' autonomy. Yet, simultaneously, creators have the power to cultivate their online spheres in such a way that protects their safety while maximizing their ability to share their identities. While consumers of their content are emboldened to say whatever they wish due to the relative anonymity that computer 
and phone screens provide, it is easier for creators to cope with this harassment online than through in-person forms of sex work. Blocking accounts and warning other creators of suspect individuals through word of mouth or online social media groups is a key way through which peace of mind is achieved. This safety net allows creators to continue to work without anxiety regarding gendered harassment. Participants feel that the context of user-generated platforms is more hospitable to those who do not meet mainstream definitions of beauty — thinness, whiteness, hyper femininity, and so on — upheld in spaces like strip clubs and webcam websites. In other words, adult content creators have the power to carve out their own images and followings while in their own corner of the internet in which they can thrive.

Harassment from consumers comes in a variety of forms, but the most recurring trend is men sending detailed sexual fantasies and/or unsolicited genitalia pictures to the creator. This form of communication is perceived as stemming from the disempowering fallacy that because creators are putting forth sexual imagery, they are seeking sexual responses. Emma describes her frustration, stating, "I get uncomfortable with people giving me heavy inquiry all the time about what they want to do to me or things they want me to do or how they want to meet me." Consequently, she has led her to consider her level of exposure, not because she is concerned about her vanilla job finding out about her adult content creation, but because she wishes to rein in the array of men sending her unwanted communication. Lilah reports that a friend of hers, a popular creator, receives paragraph-long DMs from followers communicating their affection and sexual desires. "I've been taught that boundaries are what keep you out of those 
conversations," she says. In the case of harassment, boundaries are largely set by either disregarding unwanted communication or blocking any user who chooses to escalate the situation. All participants find that cultivating their following by blocking certain profiles generally takes care of any issues. This option is a marked shift from in-person sex work where removing a problematic customer is not so simple. As India, a 26-year-old cannabis brand ambassador, elaborates:

If you're out in the world it would be a lot harder to direct people's attention if you don't want it. When you're on social media you get to choose the times when you are working [and] I'm getting to do it from the safety of my own home. To me, that's the obvious number one pro. You know where you are, you're safe. Even if you don't have a steady home base, you can do it from friends' houses.

India highlights how working from home can add a protective layer to a field of work known for gendered violence. Working outside of more formal service sector settings in which face must be maintained means more freedom to take candid approaches to harassment. Participants who are dancers place strip clubs in the more structured category, citing how they must continue to smile and remain polite when dealing with problem customers. Some report how bouncers side with customers over dancers, or simply fail to remain attentive over the course of a shift. "I can assert boundaries because I can close my computer or turn off my phone and it's over instead of having to think on the spot to get out of a situation," Skyler says, indicating that they can effectively serve as their own authority on security. Mitigating fear of harassment that can escalate into gendered violence empowers content creators to work.

In addition to being a space in which adult content creators can cultivate their audiences, user-generated platforms provide creators with the freedom to express 
themselves through creativity. "I always loved modeling and just realized there was a market I could appeal to with my content, which is mostly composed of artful nudes or teasing videos unless the client specifically asks for something more explicit," says Angel. Seeing her work as an extension of a lifelong creative passion, she feels as though she is finally able to monetize her art. Aaliyah particularly enjoyed the atmosphere on the popular blog website Tumblr while it was still a viable platform for pornography. While Tumblr banned adult content in December of 2018, her time spent cultivating her photos on the platform instilled a love of the personal creative direction that is largely absent from mainstream pornography. This appreciation is shared by other creators with whom she has connected. For Nikki, the freedom to mold her content to her own tastes is a refreshing change from the oversight that she experiences at her home strip club:

I have the option to do [what I] want to do, so, like, in the club there's laws...you know, there are parameters there. So if someone wanted to touch my butt I still can't be like yeah, you can touch my butt because the law is the way it is, so it's really nice to have the freedom of making every single executive decision over what I do with my body.

Nikki's orientation of creative freedom within bodily autonomy more broadly is one that is echoed by participants who hold marginalized identities. For Skyler, who is non-binary, and Emma, 29, who is mixed race and full-figured, being able to carve out spaces in which they can exist as they are has transformative effects. After being fired from their strip club when their gender identity was scrutinized, Skyler is able to continue supporting themself through online-based sex work, finding a specialty in reviewing toys, which are often bought for them by their audience. "Now that I've kind of established my own audience, I've kind of experimented with being more fluid with my gender,' they 
state. "I feel like people have been taking to it because I'm making my all-time high that I have been while doing content creation." In other words, presenting as their true self is not only affirming, but lucrative. Emma, who notes earning less money in the strip club when at a higher weight, also expresses enjoyment in creating a space in which she can be herself. While most participants perform solo, Emma enjoys expanding her content by working with other women and nonbinary individuals. While working with others creates more variables to manage, Emma finds it worth it in order to increase queer representation in sexualized imagery. Mandy, who is also a full-figured woman of color, notes discrimination in stripping, saying "a lot of the clubs, as you probably know, are not body positive, so I have a harder time getting contracts at like corporate clubs and things like that." A barrier to one kind of sex work has also been a bolster to another as she thrives in adult content creation, which can reach a variety of tastes and preferences outside of hegemonic beauty norms. Further, adult content creation provides a space in which women can assert their own perspectives and pleasures. For example, Riley shares that she enjoys sharing real orgasms with her content consumers, even though it may require more time than engaging in performative pleasure. Being a consumer of mainstream porn is not necessarily a prerequisite for being an adult content creator; in fact, many participants were motivated to cultivate what is not already out there, providing a voice to new populations

More broadly, the sample presents a duality of privilege in which some participants sought out sex work because they wanted to, while others followed a course like Belle. "I fell into it through desperation before realizing it was really beneficial if I 
did it in a smart way, so I just kind of maintained it and tweaked it to [my] lifestyle as I've gone on," she explains. Whether it be houselessness or drug addiction, the most vulnerable participants have followed a path to content creation, which has ultimately allowed them to go back to school or practice the business skills they have picked up along the way. In sum, the accessibility of social media opens up adult content creators to negative experiences, but it also makes it as simple to block consumers in such a way that is not possible in face-to-face sex work. Additionally, the blank slate of social media allows creators to assert their own identities in lieu of molding themselves into an ideal set by more structured forms of adult entertainment. While having one's own space to thrive outweighs the threat of harassment, harassers have the ability to report content for violating apps' terms and conditions, which persecute rather than protect adult content creators.

\section{Platform Restrictions}

While the advantages of adult content creation have largely outweighed the challenges to autonomy presented thus far, the policing of social media platforms in the wake of FOSTA-SESTA remains a definitive roadblock. The most common experience among participants is shadow banning, which is when a user's content no longer appears in news feeds, and their handle no longer appears in app-wide searches. While users are not notified when they are shadow banned, they find out when other users inform them that they have not been seeing their posts or that their handle is not searchable. This measure impedes on a creator's ability to interact with their followers and recruit new ones, which has a detrimental effect on their economic independence. Some participants 
have had their accounts entirely deleted, and with it, the following and body of work they have worked to cultivate. If participants have not had their accounts deleted, they know someone who has. This looming threat to their stability as autonomous workers creates anxiety among creators. Consequently, some participants have been moving to the OnlyFans - a platform where consumers can pay directly through the website in order to view creators' content. While OnlyFans also hosts vanilla content creators, the platform is perceived as tolerant towards online sex workers. Yet, it raises some similar restrictions to webcamming. The platform takes a cut of creators' earnings and it takes one week to process transaction. Also, it requires users to leave hyper mainstream apps to find content, which has only become more complicated since its app has been banned from major app stores.

Upon being passed in 2018, FOSTA-SESTA had an immediate effect on fullservice sex workers. Skyler, who had been successful in full-service work, expresses the following: "I was mentally just worried because I went from feeling like I had so much opportunity to just nothing and so I was definitely worried that I was going to run out of money." Skyler advertised on Backpage and had room to be picky about their clients, who had to undergo a vetting process. After FOSTA-SESTA, they no longer had this privilege, which ultimately led them to "ignore red flags" about a suspect client, who ended up assaulting and robbing them. "I totally, totally blame that on FOSTA and SESTA because if I wouldn't have been so desperate, I wouldn't have been put in that situation where I wouldn't have gone against my own gut and gone against what I know to be right," they reflect. FOSTA-SESTA impeded on client vetting processes as the 
influence of legal liability rippled across the internet. Belle notes that the message boards hosting the networks she established with other sex workers have been removed, leaving them without a space to share when a client was been problematic or acted dangerously. As the effects of FOSTA-SESTA continue to bleed out into user-generated platforms, adult content creators' accounts are endangered. Being suddenly left without a place to work is a definitive threat to autonomy. In many cases, it only takes one report or flag from a resentful user or administrator perpetuating "phobic bullshit," as Belle explains, to negatively affect an account. Multiple participants cite being shadow banned. Using certain hashtags or sharing links to other sex work accounts can put creators at risk as much as a picture that is deemed too risqué, which undercuts their ability to recruit new customers, particularly among lucrative kink communities. Veronica, 39, explains that platforms such as Phrendly are occasionally shadow banned from app stores entirely, impeding on her ability to leverage potential users she meets at the strip club. The underlying anxiety that this risk breeds hinders their sense of stability. Nikki elaborates on this feeling:

I haven't [been shadow banned or deleted], and I'm not quite sure how, but I haven't. That's one of the things I've been like waiting for. Like, well, when am I going to get shadow banned or when am I going to have my commenting turned off. I'm, like, waiting for it. It never happens, or it hasn't happened yet, which is a good thing, but it is something that I'm kind of twiddling my thumbs waiting for.

While some participants were waiting for their accounts to be deleted, others were wellversed in being deplatformed. While experiences with policing on Twitter and Snapchat varied among participants (speaking to the arbitrary enforcement of app terms and conditions), experiences on Instagram were generally negative. Not only does Instagram 
allow an ambiguous degree of nudity, it permits male nipples to be shown, but not female. Lilah, who has had multiple Instagram accounts deleted, also notes that adult content creators who participate in sex work activism tend to have their accounts targeted. She reports that an alternative model had her account deleted after demonstrating in front of Instagram's headquarters. In sum, policing on user-generated platforms not only affect creators' ability to host and sell content, but it infringes are sex worker solidarity and discourse.

One of the responses to shadow banning and deletion has been to migrate to OnlyFans. Through a transaction that goes directly through the site, customers have access to an unlimited amount of content for a set user. While this platform serves as a more secure space to keep content safe, it reimposes some of the restrictive features of more traditional forms of sex work, as users must pay out to a host in order to feel protected. It is also uncertain if OnlyFans will begin cracking down on adult content creation in the wake of FOSTA-SESTA in the same fashion as its similarly structured competitor, Patreon. While adult content creation is not technically illegal, it is being regulated by app terms and conditions out of fear that the platform will be subject to policy scrutiny in the wake of FOSTA-SESTA. While work oriented in the informal economy may not be subject to the red tape of bureaucratic structures in the formal economy, gendered inequalities are reinforced through a trickledown effect of policing. At the top, FOSTA-SESTA imposes a new jurisdiction of legal liability, which leads to deplatforming and shadow banning and the ground level. The latter would not exist to the same extent without the former. 
Chapter 6

Conclusion

Adult content creation is the latest development in the well-developed historical timeline of sex work. The advent of the internet facilitated the development of webcam websites as well as message boards where full-service sex workers advertise. More recently, sex work has emerged from niche communities, finding a home on hypermainstream social media apps in the form of adult content creation. Adult content creators have subsequently found themselves navigating a unique set of circumstances, which leads to distinct consequences for their autonomy as workers. Running an entrepreneurial enterprise, performing feminized labor, and negotiating direct relationships with clients define the daily lives of online sex workers. Maximizing income streams is a top priority for creators, who have found a lack of stability in other forms of adult entertainment as well as in vanilla work.

Hustling outside of formal economic settings means unprecedented flexibility, particularly for creators who are managing other businesses, family obligations, and/or educational commitments. The hustle can also involve an insatiable drive for innovation with little eligibility for tax breaks. The demand for the girlfriend experience can provide a sense of purpose for some creators, while many others must actively set barriers to protect their investment of time and emotional labor. Performing gendered work also means having to cope with disempowering sexual harassment from customers who believe that sex workers are welcoming explicit conversations by virtue of working in adult entertainment. While all of these conditions can be challenging, creators are highly 
adaptive, developing ways to overcome certain barriers while maximizing their creativity, incomes, and ultimately, autonomy.

While personal boundaries are enforced by setting working hours, reining in custom requests, and blocking problematic consumers, overcoming the trickle-down effect of FOSTA-SESTA is more arduous. Deletion and shadow banning are common experiences among creators, who are vocal about the censorship of the human body. Because this censorship disproportionately affects users who share feminine imagery, infringement on bodily autonomy reflects the devaluation of feminized labor. Creators link the heightened surveillance by app algorithms and administrators to the legal liability of platforms imposed by FOSTA-SESTA. When bearing in mind that many creators recognized the market for adult content creation as other forms of sex work has become a less profitable use of their time, a pattern begins to emerge: as sex work continues to evolve, so do efforts to hamper the autonomy of its workers.

In the beginning, creators were able to develop their place in a new budding market, but their businesses have slowly been encroached upon by regulation imposed by a structure of both public and private censorship. A pyramid of policing has formed: federal regulations act at the top, dictating the criminal jurisdiction of the internet, while app terms and conditions work at the ground level, enforcing self-serving regulations at the expense of users. The result is a direct impediment on adult content creators' autonomy by taking away the means of performing their job at the most essential level. This scope of policing acts as the organization enforcing gendered inequality in the absence of a formal bureaucratic structure. By limiting opportunities for women and 
gender minorities across all economic spheres, the chances of becoming upwardly mobile remain low and the status quo gender dynamics are retained.

FOSTA-SESTA, like many other initiatives addressing sex work, formally aims to address the global issue of human trafficking in the United States. Yet, the experiences of creators indicate that this legal package has destabilized their safety and security at the most basic level, in addition to their autonomy as workers. While adult content creation was a good alternative to the tumultuous conditions that full-service sex workers faced after the shuttering of Backpage and Craigslist personal ads, it has since been subject to scrutiny by its hosting platforms, who are taking discriminatory precautions to avoid criminal liability. While adult content creation is coercive insofar as all paid labor is coercive, there is a population of sex workers online who are working within the guidelines of sexual consent. This research is not claiming that all online sex workers work under homogenous conditions, nor does it aim to undermine the harsh realities of human trafficking. Rather, it is arguing that measures like FOSTA-SESTA do a disservice to sex workers who operate consensually, as well as to those who are being trafficked. Because both conditions are effectively being conflated, resources that could be used to stop trafficking are being expended on those working consensually, which increases vulnerability for both populations. Those working consensually lose the power to safely advertise and vet their clients, and those who are truly being trafficked are being overlooked in the process. In order to undercut human trafficking while ensuring the autonomy of consensual workers, rethinking the laws governing consensual sex work by treating sex worker rights as worker rights is essential. 
However, given the apparent economic implications of policing sex work, it is unlikely that motivations are strictly about eliminating trafficking. Historically marginalized populations who subsist outside of the formal economy are targets of policing because their labor is going to their personal benefit rather than that of larger corporate entities. Women and gender minorities are pushed away from seeking sex work as an alternative to, or a supplement for, the low wage service and ghettoized administrative sectors through the threat of policing. In the case of adult content creation, this discouragement takes form in the anxiety stemming from sudden deplatforming. So, while more effective legislation of combatting human trafficking can be proposed, sex workers are unlikely to be considered a population of workers whose autonomy is worth defending as long as their labor can be exploited in the most vulnerable sectors of the formal economy.

Like with many studies investigating hard-to-reach populations, the data guiding these claims is limited by a small sample size. Snowball sampling can also impede on diversity, as operating through personal networks taps into a more homogenous population. Saturation was achieved on topics such as emotional labor and workplace flexibility, but the lack of extensive racial diversity among the sample was not ideal. While both mixed-race participants were forthcoming in their experiences, it is not to be implied that two women of color are representative of all content creators of color. Thus, future research on adult content creators of color is necessary to corroborate this study's findings. It is also not to be implied that a single non-binary participant can represent all non-binary creators. Achieving a larger sample size would increase the likelihood that 
more non-binary individuals are represented. As the story of adult content creation continues to unfold, a more comprehensive experience can be shared. Optimism remains that adult content creation is a space in which workers can openly display their unique set of identities.

While the advancement of sex worker rights is at odds with economic interests, the participants, who already demonstrated resilience in so many other facets of their work, indicate that they do not plan to relent on surviving as proud sex workers. Rather, they aim to have their voices heard by speaking with the press, getting involved in local politics, engaging in demonstrations, forming networks among other sex workers, and in many cases, simply being present online. The collective solidarity that a vast platform like the internet provides will continue to be a key tool in mobilization. While the reinforcement of gender inequalities in the economy is institutionalized, it will become more challenging to keep sex workers silent about the conditions within the presiding organization, one defined by surveillance, regulation, and censorship. 


\section{References}

Acker, Joan. 2006. "Inequality Regimes: Gender, Class, and Race in Organizations." Gender \& Society 20(4):441-64.

Allow States and Victims to Fight Online Sex Trafficking Act and Stop Enabling Sex Traffickers Act of 2017, Public Law 115-164, 132 Statutes at Large 1253 (2018).

Andersson, Matthew A. and Catherine E. Harnois. 2020. "Higher Exposure, Lower Vulnerability? The Curious Case of Education, Gender Discrimination, and Women's Health." Social Science \& Medicine 246(1):1-11.

Bernstein, Elizabeth. 2008. "Sex Work for the Middle Classes." Sexualities 10(4):473 -88 .

Carbonero, M. Antònia and María Gómez Garrido. 2017. "Being Like Your Girlfriend: Authenticity and the Shifting Borders of Intimacy in Sex Work." Sociology 52(2):384-99.

Cook, Jennifer. 2005. "Shaken from Her Pedestal: A Decade of New York City's Sex Industry Under Siege." The City University of New York Law Review 9(1):121-59.

Christensen, MacKenzie A. 2018. ““Tindersluts' \& 'Tinderellas:' Examining Young Women's Construction and Negotiation of Modern Sexual Scripts within a Digital Hookup Culture." PhD dissertation, Department of Sociology, Portland State University.

Danna, Daniela. 2012. "Client-Only Criminalization in the City of Stockholm: A Local Research on the Application of the 'Swedish Model' of Prostitution Policy." Sexuality Research and Social Policy 9(1):80-93.

Dewey, Susan. 2012. "The Feminized Labor of Sex Work: Two Decades of Feminist Historical and Ethnographic Research." Labor 9(2):113-32.

Ebner, Alexander. 2005. "Entrepreneurship and Economic Development: From Classical Political Economy to Economic Sociology." Journal of the History of Economic Thought 28(3):315-32.

Edwards, Paul. 2003. Industrial Relations: Theory and Practice. Malden, MA: Blackwell.

Ettachfini, Leila. 2018. "Users Accuse Instagram of Censoring Hashtags about Sex Work and Women." Vice, March 23. Retrieved March 2, 2020 (https://www.vice.com/en_us/article/xwmg3j/instagram-sesta-fosta-censorship hashtagwoman.com). 
Ferguson, Ann, Rosemary Hennessy, and Mechthild Nagel. 2019. "Feminist Perspectives on Class and Work." The Stanford Encyclopedia of Philosophy, edited by Edward N. Zalta. Retrieved March 2, 2020 (https://plato.stanford.edu/entries/feminism class/).

Frith, Hanna. 2015. 'Visualizing the 'Real' and the 'Fake:' Emotion Work and the Representation of Orgasm in Pornography and Everyday Sexual Interactions." Journal of Gender Studies 24(4):386-98.

Genç, Merve and Burcu Öksüz. 2015. “A Fact or an Illusion: Effective Social Media Usage of Female Entrepreneurs." Procedia - Social and Behavioral Sciences 195:293-300.

Guest, David E. 2002. "Perspectives on the Study of Work-life Balance." Social Science Information 41(2):255-79.

Guy, Mary Ellen and Meredith A. Newman. 2004. "Women's Jobs, Men's Jobs: Sex Segregation and Emotional Labor." Public Administration Review 64(3):289-98.

Handyside, Sarah and Jessica Ringrose. 2017. "Snapchat Memory and Youth Digital Sexual Cultures: Meditated Temporality, Duration and Affect." Journal of Gender Studies 26(3):347-60.

Jaffee, David. 1989. "Unbinding Time: Alternate Work Schedules and Work-Life Balance." Social Science Quarterly 70(2):375-90.

Jones, Angela. 2015. "For Black Models Scroll Down: Webcam Modeling and the Racialization of Erotic Labor.” Sexuality and Culture (19)4:776-99.

Maher, JaneMaree, Sharon Pickering, and Alison Gerard. 2012. "Privileging Work Not Sex: Flexibility and Employment in the Sexual Services Industry." The Sociological Review (60):654-75.

Merrit, Kennedy. 2018. "Craigslist Shuts Down Personals Section After Congress Passes Bill On Trafficking.” NPR, March 23. Retrieved March 2, 2020 (https://www.npr.org/sections/thetwo-way/2018/03/23/596460672/craigslist shuts-down personals-section-after-congress-passes-bill-on-traffickin).

Parthasarathy, Padmini. "New Orleans' Tourism Goals Threaten Entertainers.” Next City, August 5. Retrieved March 2, 2020 (https://nextcity.org/features/view/new orleans-tourism-goals-threaten-entertainers).

Pierce, Jennifer L. 1999. "Emotional Labor Among Paralegals." Annals of the American Academy of Political and Social Sciences 561(1):127-42. 
Price-Glynn, Kim. 2010. Strip Club: Gender, Power, and Sex Work. New York: New York University.

Sanders, Teela, Laura Connelly, and Laura Jarvis King. "On Our Own Terms: The Working Conditions of Internet-Based Sex Workers in the UK." Sociological Research Online 21(4) doi: 10.5153/sro.4152.

Schor, Juliet B. 1991. The Overworked American: The Unexpected Decline of Leisure. New York: Basic Books.

Stanley, Nick, and Christine Barter, Marsha Wood, Nadia Aghtaie, Cath Larkins, Alba Lanau, and Carolina Överlien. 2018. "Pornography, Sexual Coercion and Abuse and Sexting in Young People's Intimate Relationships." Interpersonal Violence 33(19):2919-44.

Tavares, Susana M. 2016. "How Does Creativity at Work Influence Employee's Positive Affect at Work?" European Journal of Work and Organizational Psychology 25(4):525-39.

Tiffany, Kaitlyn. 2019. “Tumblr's First Year Without Porn.” The Atlantic, December 3. Retrieved March 2, 2020 https://www.theatlantic.com/technology/archive/2019/12/tumblr-year-review2019-nsfwban-memes/602911/).

Truss, Catherine J. G. 1993. The Secretarial Ghetto: Myth or Reality. Work, Employment \& Society 7(4):561-84.

United States Department of Homeland Security. "What Is Human Trafficking?" Retrieved March 3, 2020 (https://www.dhs.gov/blue-campaign/what-human trafficking).

Vakhitova, Zarina, Julianne Webster, Clair Alston-Knox, Danielle Reynald, and Michael Townsley. 2018. "Offender-victim Relationship and Offender Motivation in the Context of Indirect Cyber Abuse." International Review of Victimology 24(3):347-66.

van der Meulen, Emily. 2012. "When Sex is Work: Organizing for Labour Rights and Protections." Labour / Le Travail 69(1):147-67.

van Doorn, Niels and Olav Velthuis. 2018. "A Good Hustle: The Moral Economy of Market Competition in Adult Webcam Modeling." Journal of Cultural Economy 11(3):177-92.

Vitale, Alex S. 2017. The End of Policing. Brooklyn: Versa.

Weber, Max. 2012. The Protestant Ethic and the Spirit of Capitalism. New York: Dover. 